\title{
XRD analysis for hydration products of different lime-pozzolan systems
}

\author{
Nahida Kadum $^{1}$, Zeyad Al-Azzawi ${ }^{2}$, and Tareq al-Attar ${ }^{2, *}$ \\ ${ }^{1}$ Ministry of Youth and Sport, Baghdad, Iraq \\ ${ }^{2}$ University of Technology, Baghdad, Iraq
}

\begin{abstract}
This study represents a part of an extensive experimental program devoted to study the properties of different Lime-Pozzolan systems as a sustainable binder to replace Portland cement in concrete. These systems were Lime-Silica fume, Lime-Silica fume-Fly ash and Lime-Metakaolin. Four powder samples for X-ray diffraction, XRD, analysis was prepared from the studied systems. These samples were chosen to monitor the effect of curing age on the hydration process and to study the difference in hydration products when using different binder systems. According to the defined minerals by XRD analysis, the hydration products of all investigated Lime-Pozzolan mixtures are closely similar to those of Portland cements. The current XRD analyses have been employed to build recommendations for the forecast performance for each system.
\end{abstract}

\section{Introduction}

Utilizing of natural Pozzolan, such as volcanic ash, in combination with Lime to produce hydraulic concretes was first done by the Romans. Two millenniums old structures, including the Pantheon, are a good proof to the strength and durability of this ancient material [1]. Lime-natural Pozzolan cements were widely used for all kinds of construction as the earliest important building materials. The invention of Lime and Lime-natural Pozzolan cements backs to the Neolithic period, 7000 BC. They were widely used in the masonry construction of aqueducts, arch bridges, retaining walls and buildings during Roman times [2]. In the middle and late 19th century, such binders were commonly used for plain concrete structures, often in combination with crushed bricks as coarse aggregate for Dutch military works [3]. The use of Lime-natural Pozzolan cements, however, had not been continued due to some disadvantages such as: long setting time and low early-age strength. On the other hand, Lime-natural Pozzolan cements have a number of advantages including low cost and more importantly long-term engineering properties such as very low heat evolution, decreased permeability and increased chemical resistance. The invention of Portland cement in the 19th century resulted in a drastic reduction in use of Lime-natural Pozzolan cement because of the faster setting time and higher early-age strength of Portland cements. In recent decades, the environmental side-effects of Portland cement production process have caused a growing interest in the demand of LimePozzolan binders [2]. The manufacture of Portland cement is an energy and carbon intensive process and it is responsible for 5 to 8 percent of the total global carbon emissions [4].

X-Ray Diffraction, XRD, is a technique used to determine the mineral properties of a crystalline solid. When a crystalline solid is exposed to X-Rays of a particular wavelength, layers of atoms diffract and produce a pattern of peaks, which characterize the minerals present in the material [5]. Powder XRD has numerous advantages like non-destructive nature, high sensitivity, reliability, easy sample preparation, system is user friendly, operational procedure is convenient, easy data interpretation that could be used for both qualitative and quantitative analysis, in wide range of applications. Since every material has its unique diffraction patterns so materials and compounds can be identified by using a database of diffraction patterns [6].

Lime-Pozzolan systems could be considered as promising new binders; therefore, the aim of this study is to investigate the XRD patterns for these mixtures. This investigation will enrich the available database and could give an indication about the effect of the chemical composition on the behavior of these mixtures in their service life.

\section{Experimental work}

\subsection{Lime-Pozzolan mixture}

In an extensive experimental program, three different Lime-Pozzolan systems were investigated. The program was mainly devoted to study these systems as a sustainable binder to replace Portland cement in

Corresponding author: 40076@uotechnology.edu.iq 
concrete, for more details see Kadum [7]. The systems were Lime-Silica fume, LS, Lime-Silica fume-Fly ash, LSF, and Lime-Metakaolin, LMK. Tables 1and 2 show the chemical composition and physical properties of hydrated Lime, Silica fume, Fly ash and Metakaolin, respectively. Table 3 lists the mix proportions for the produced concrete throughout this study.

Table 1. Chemical and physical properties of hydrated lime

\begin{tabular}{|c|c|c|}
\hline \multicolumn{2}{|c|}{ Test } & Results \\
\hline \multirow{2}{*}{$\begin{array}{c}\text { Chemical } \\
\text { Composition, } \\
\%\end{array}$} & $\mathrm{CaO}$ & 86.444 \\
\cline { 2 - 3 } & $\mathrm{MgO}$ & 2.14 \\
\cline { 2 - 3 } $\mathrm{CO}_{2}$ & 2.47 \\
\hline \multicolumn{2}{|c|}{ Chemical Factor } & 84.2 \\
\hline \multicolumn{2}{|c|}{ Blaine Fineness, $\mathrm{m}^{2} / \mathrm{kg}$} & 1200 \\
\hline \multicolumn{2}{|c|}{ Pozzolanic Receptivity Index, \% } & 101.04 \\
\hline
\end{tabular}

Table 2. Chemical composition and physical properties of used Silicafume, Fly ash and Metakaolin.

\begin{tabular}{|c|c|c|c|c|}
\hline \multicolumn{2}{|c|}{ Pozzolana Type } & SF & FA & MK \\
\hline \multirow{4}{*}{$\begin{array}{c}\text { Chemical } \\
\text { Composition, } \\
\%\end{array}$} & $\mathrm{SiO}_{2}$ & 90.64 & 65.65 & 51.35 \\
\cline { 2 - 5 } & $\mathrm{Al}_{2} \mathrm{O}_{3}$ & 0.02 & 17.69 & 22.4 \\
\cline { 2 - 5 } & $\mathrm{Fe}_{2} \mathrm{O}_{3}$ & 0.01 & 5.98 & 2.3 \\
\cline { 2 - 5 } & $\mathrm{CaO}$ & 1.21 & 0.98 & 3 \\
\cline { 2 - 5 } & $\mathrm{MgO}$ & 0.01 & 0.72 & 0.17 \\
\cline { 2 - 5 } & $\mathrm{SO}_{3}$ & 0.23 & 0.19 & 0.15 \\
\cline { 2 - 5 } & $\mathrm{LOI}$ & 2.86 & 3.1 & 7.8 \\
\hline \multicolumn{2}{|c|}{ Blaine Fineness, $\mathrm{m}^{2} / \mathrm{kg}$} & 20000 & 773 & 1100 \\
\hline \multicolumn{2}{|c|}{ Specific Gravity } & 2.35 & 2.26 & 2.48 \\
\hline
\end{tabular}

Table 3. Mix proportions for different Lime-Pozzolan systems.

\begin{tabular}{|c|c|c|c|}
\hline Mix & LS & LSF & LMK \\
\hline Lime, $\mathrm{kg} / \mathrm{m}^{3}$ & 166 & 200 & 200 \\
\hline $\mathrm{SF}, \mathrm{kg} / \mathrm{m}^{3}$ & 166 & 80 & --- \\
\hline $\mathrm{FA}, \mathrm{kg} / \mathrm{m}^{3}$ & --- & 120 & --- \\
\hline $\mathrm{MK}, \mathrm{kg} / \mathrm{m}^{3}$ & --- & --- & 200 \\
\hline Fine aggregate, $\mathrm{kg} / \mathrm{m}^{3}$ & 680 & 704 & 704 \\
\hline Coarse aggregate, $\mathrm{kg} / \mathrm{m}^{3}$ & 1020 & 1056 & 1056 \\
\hline Water, $\mathrm{kg} / \mathrm{m}^{3}$ & 166 & 160 & 198 \\
\hline HRWR, $\%$ of L+P & 2.5 & 1 & 2.5 \\
\hline
\end{tabular}

\subsection{XRD test}

The test was conducted in the Nanotechnology and Advanced Materials Research Center, University of Technology. Figure 1 shows the X-ray Diffraction apparatus. Four powder samples were prepared for the test. They were chosen as follows:

a. Two samples from the Lime-Silica fume mixture at ages of 7 and 90 days to monitor the effect of curing age on the hydration process.

b. Two samples from mixes Lime-Silica fume-Fly ash and Lime-Metakaolin mixtures at the age of 90 days to study the difference in hydration products when using different binders.

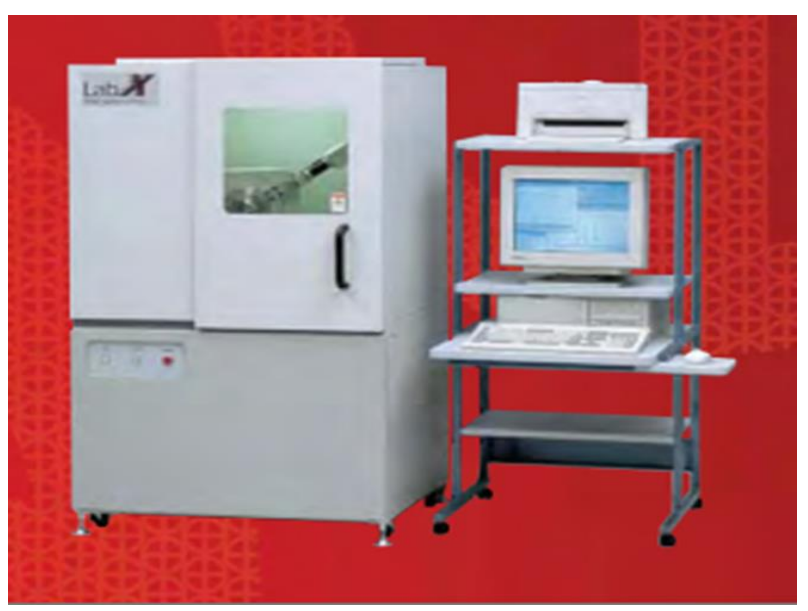

Fig. 1. X-ray diffraction apparatus

\section{Analysis and discussion of XRD results}

Table 4 and Figures 2 - 5 display the result of the XRD of powder samples taken from mixes LS, LSF and LMK. Data of XRD powder, listed in Appendix 3 in reference No. 8, were adopted to define the minerals represented by peaks in Figures $2-5$. According to the defined minerals, it could be concluded that the hydration products of Lime-Pozzolan mixtures are closely similar to those of Portland cements.

Table 4. Summary of results of the XRD of powder samples taken from mixes LS, LSF and LMK.

\begin{tabular}{|c|c|c|c|c|c|c|}
\hline Mix & $\begin{array}{l}\text { Age, } \\
\text { days }\end{array}$ & $\begin{array}{l}\text { High } \\
\text { Peaks }\end{array}$ & $\begin{array}{c}\text { Peak } \\
\text { No. }\end{array}$ & $\begin{array}{c}2 \text { theta, } \\
\text { deg. }\end{array}$ & $\mathbf{d}, \mathbf{A}^{\mathbf{0}}$ & $\begin{array}{c}\text { Rel. } \\
\text { Int., } \\
\%\end{array}$ \\
\hline \multirow{6}{*}{ LS } & \multirow{3}{*}{7} & 1 & 4 & 26.7 & 3.34 & 100 \\
\hline & & 2 & 1 & 11.7 & 7.53 & 73 \\
\hline & & 3 & 5 & 29.39 & 3.04 & 58 \\
\hline & \multirow{3}{*}{90} & 1 & 7 & 29.5 & 3.02 & 100 \\
\hline & & 2 & 1 & 11.8 & 7.49 & 66 \\
\hline & & 3 & 3 & 21.0 & 4.21 & 52 \\
\hline \multirow{3}{*}{ LSF } & \multirow{3}{*}{90} & 1 & 6 & 29.6 & 3.02 & 100 \\
\hline & & 2 & 1 & 11.9 & 7.45 & 55 \\
\hline & & 3 & 5 & 26.8 & 3.32 & 52 \\
\hline \multirow{3}{*}{ LMK } & \multirow{3}{*}{90} & 1 & 14 & 29.7 & 3.01 & 100 \\
\hline & & 2 & 9 & 23.2 & 3.83 & 81 \\
\hline & & 3 & 12 & 26.9 & 3.31 & 69 \\
\hline
\end{tabular}

\subsection{Effect of binder type on hydration products}

Figures 2 and 3 show the XRD patterns for LS mix, which incorporate Silica fume as a Pozzolanic material. The only detected phases in the examined powders are the calcium silicate, $\mathrm{CS}$, calcium hydroxide, $\mathrm{CH}$, and quartz, Q. The occurrence of other phases such as: calcium aluminate, $\mathrm{CA}$, calcium ferrite, $\mathrm{CF}$, and calcium sulphoaluminate, CAS̆ have not been detected. This observation is expected since Silica fume has the highest $\mathrm{SiO}_{2}$ content in all Pozzolan. These patterns were in agreement with the work of Chow and Barbhuiya [5] Bottrill [9] and Bernd [10]. 


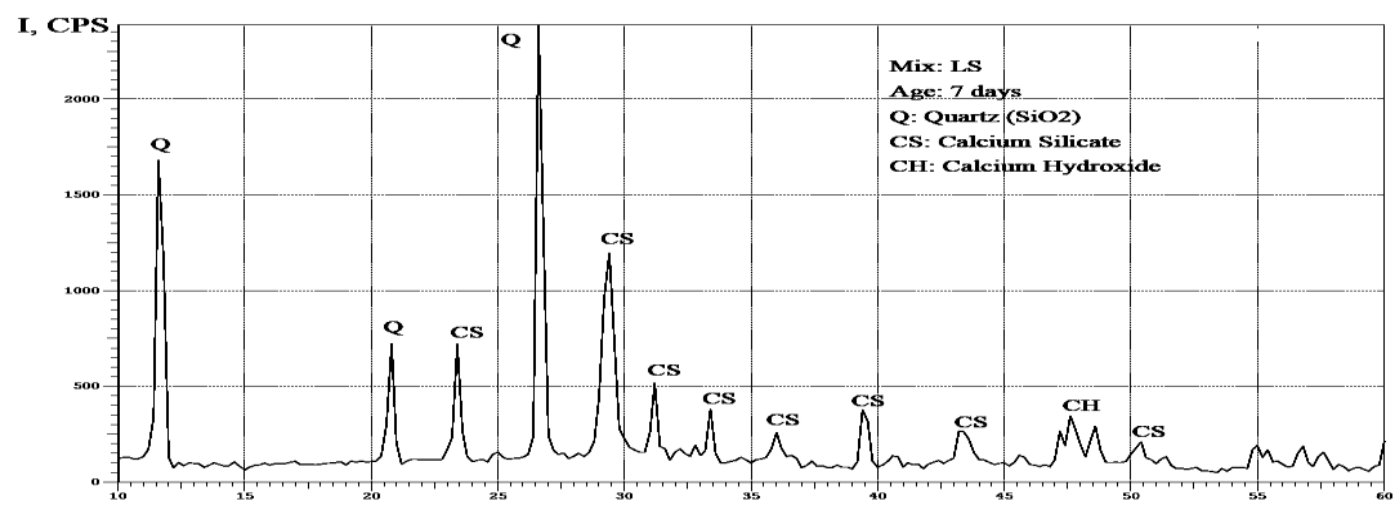

2 Theta, deg

Fig. 2. XRD pattern for mix LS at age of 7 days.

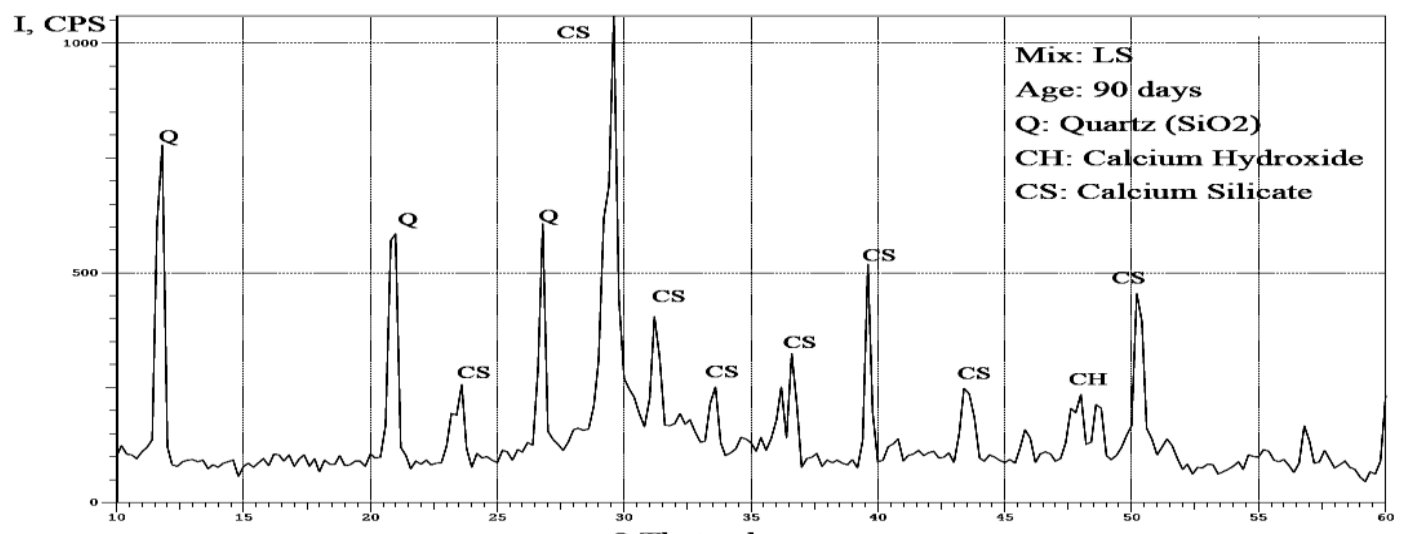

Fig. 3. XRD pattern for mix LS at age of 90 days.

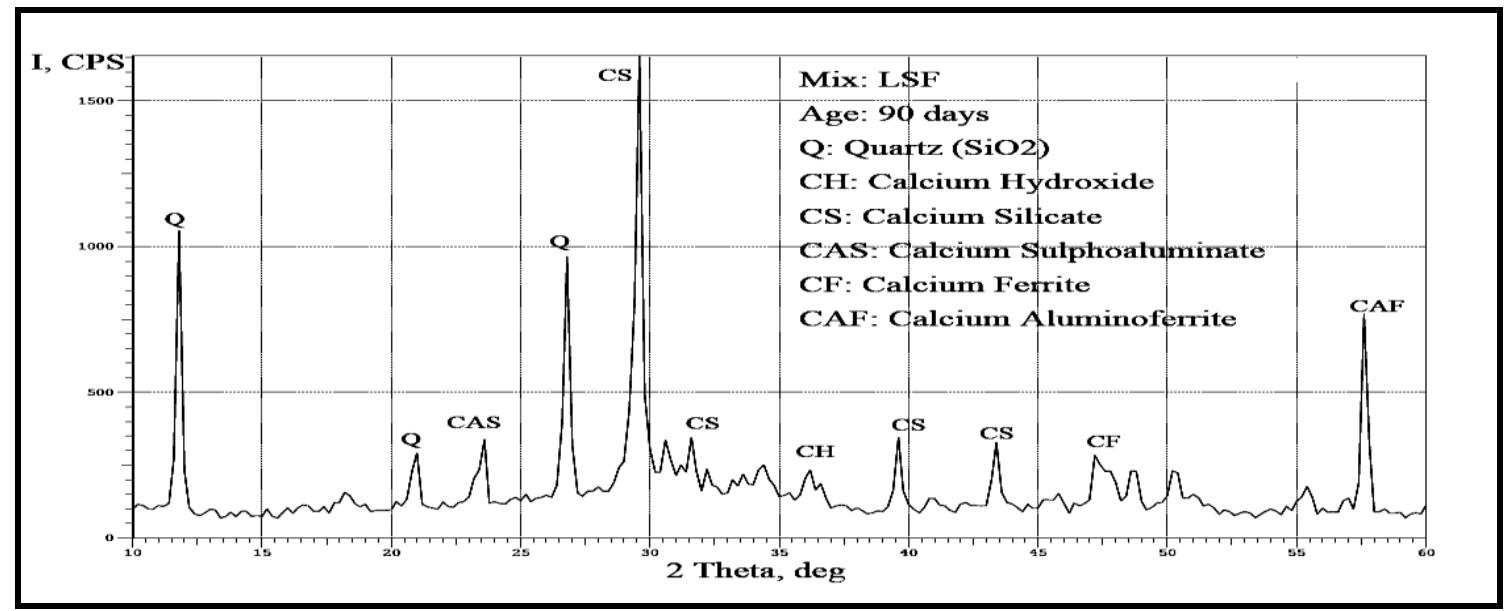

Fig. 4. XRD pattern for mix LSF at age of 90 days. 


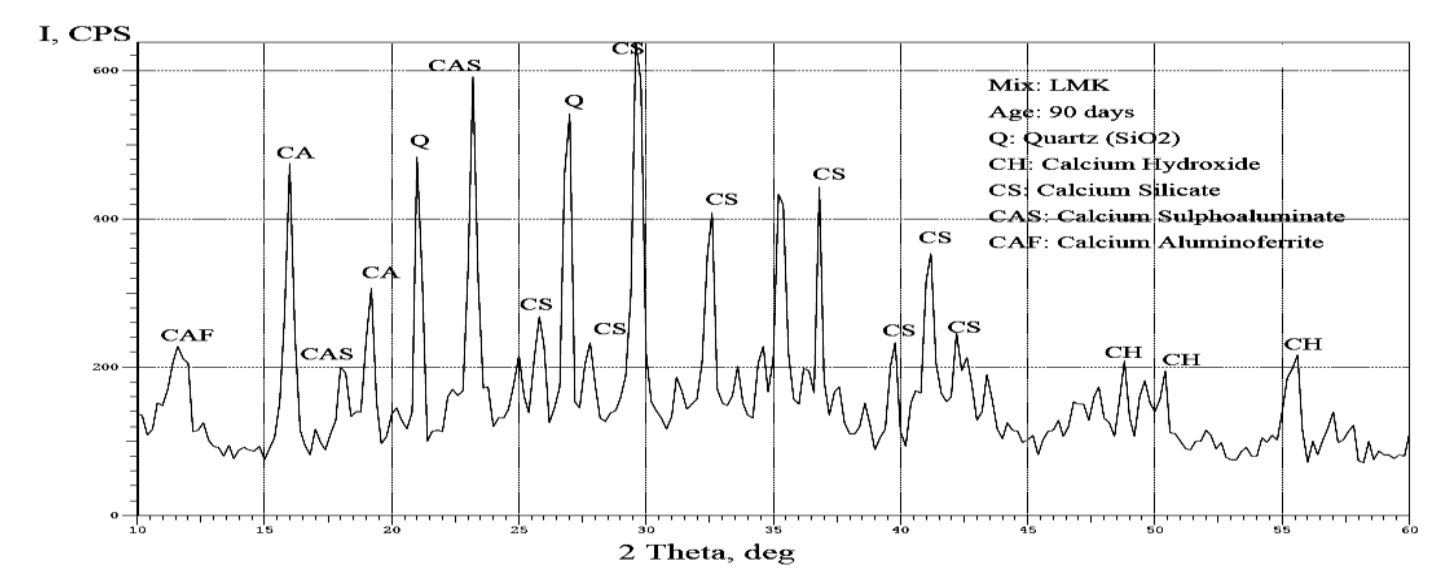

Fig. 5. XRD pattern for mix LMK at age of 90 days.

Figure 4 shows the XRD pattern for LSF mix at the age of 90 days. Due to the existence of $\mathrm{Al}_{2} \mathrm{O}_{3}, 18$ percent, and $\mathrm{Fe}_{2} \mathrm{O}_{3}, 6$ percent, in Fly ash, calcium aluminoferret, $\mathrm{CAF}$, calcium ferrite, $\mathrm{CF}$, and calcium sulphoaluminate, CAŠ have been detected in the powder in addition to the calcium silicate, $\mathrm{CS}$, calcium hydroxide, $\mathrm{CH}$, and quartz, $\mathrm{Q}$ phases. Similar patterns had been reported by Ward and French [11]. No traces of calcium aluminate, CA, phase was found. Although this observation gives the impression that this mixture is immune to sulfate attack, but the durability of LSF mixture to such attack should be investigated. Moreover, calcium aluminate has a passivity action on steel reinforcement corrosion process in reinforced concrete; therefore, the resistance of this mixture to steel corrosion should also be investigated. When examining Figure 5 that displays the XRD pattern for the mix LMK at 90 days, the main observation is the existence of calcium aluminate, $\mathrm{CA}$, phase in addition to all mentioned above phases.

That could be resulted due to the effect of both the higher content of $\mathrm{Al}_{2} \mathrm{O}_{3}, 33$ percent, and the lower content of $\mathrm{Fe}_{2} \mathrm{O}_{3}, 2$ percent, in Metakaolin. The same precautions that are recommended for Portland cements against sulfate attack should be taken. The examined XRD pattern for mix LMK was in agreement with the work of Gameiro et al. [12], Mlinárik and Kopecskó [13] and Santos Silva et al. [14].

Based on the above mentioned data, it could be concluded that the hydration products of the LimePozzolana systems depending on the silica to alumina ratio in the Pozzolanic material. Also it could be outlined here that the obtained products are closely similar to those of Portland cements, i.e. calcium silicate, calcium aluminate, calcium hydroxide and calcium sulfoaluminate.

\subsection{Effect of curing age on hydration products}

A comparison between the XRD patterns for mix LS in Figure 2, for the age of 7 days, and in Figure 3, for age 90 days, could be made to detect the effect of curing age on hydration products. The rise of calcium silicate, CS, peaks is the main difference between the two figures. In contrast to that, the quartz, Q, peaks have been dropped down due the involvement of the $\mathrm{SiO}_{2}$ in the reaction with $\mathrm{CaO}$ to produce calcium silicate, $\mathrm{CS}$.

\section{Conclusions}

1. According to the defined minerals by XRD analysis, the hydration products of the Lime-Pozzolana systems depending on the silica to alumina ratio in the Pozzolanic material. Also it could be outlined here that the obtained products are closely similar to those of Portland cements, i.e. calcium silicate, calcium aluminate, calcium hydroxide and calcium sulfoaluminate.

2. The only detected phases in the examined Lime-Silica fume powder are the calcium silicate, $\mathrm{CS}$, calcium hydroxide, $\mathrm{CH}$, and quartz, Q. The occurrence of other phases such as: calcium aluminate, CA, calcium ferrite, $\mathrm{CF}$, and calcium sulphoaluminate, CAŠ have not been detected.

3. In the powder of Lime-Silica fume-Fly ash system, calcium aluminoferret, $\mathrm{CAF}$, calcium ferrite, $\mathrm{CF}$, and calcium sulphoaluminate, CAŠ have been detected in addition to the calcium silicate, CS, calcium hydroxide, $\mathrm{CH}$, and quartz, Q phases. No traces of calcium aluminate, CA, phase was found.

4. For the mix LMK, the XRD pattern showed the existence of calcium aluminate, $\mathrm{CA}$, phase in addition to all mentioned above phases.

\section{References}

1. R. W. Steiger, Aberdeen Group. Pub. No. C950949 (1995)

2. A. Allahverdi, and J. Ghorbani, J. CeramicsSilikáty 50, 4 (2006)

3. H. A. Heinemann, O. Çopuroğlu, T. G. Nijland, Delft University of Technology (2010) 
4. E. R. Grist, K. A. Paine, A. Heath, J. Norman, H. Pinder, J. case studies in construction materials, Elsevier 1 (2014)

5. P. L. Chow, S. Barbhuiya, ISEC Press (2014)

6. A. Chauhan, P. Chauhan, J. Analytical and Bioanalytical Techniques, 5, 5 (2014)

7. N. M. Kadum, MSc Thesis, University of Technology, Iraq (2015)

8. F. M. Lea, Edward Arnold, UK (1970)

9. R. S. Bortrill, Tasmania Department of Resources and Energy - Report 1991/12, (1991)

10. F. Bernd, Proc. 10th Int. Inorganic-Bonded Fiber Composites Conference, IIBCC São Paulo, Brazil (2006)

11. C. R. Ward, D. French, Proc. World of Coal Ash, WOCA, Kentucky, USA (2005)

12. A. Gameiro, A. Santos Silva, R. Veiga, A. Velosa, MATEC9, 46, 2, (2012)

13. L. Mlinárik, K. Kopecskó, Civil Engineering \& Architecture, 56, 2 (2013)

14. A. Santos Silva, A. Gameiro, J. Grilo, R. Veiga, A. Velosa, Applied Clay Science, 88, (2014) 